\begin{tabular}{|c|c|c|c|c|c|c|}
\hline \multirow{4}{*}{ Impact Factor: } & ISRA (India) & $=3.117$ & SIS (USA) & $=0.912$ & ICV (Poland) & $=6.630$ \\
\hline & ISI (Dubai, UAE & $=0.829$ & РИНЦ (Russia & $=0.156$ & PIF (India) & $=1.940$ \\
\hline & GIF (Australia) & $=0.564$ & ESJI (KZ) & $=8.716$ & IBI (India) & $=4.260$ \\
\hline & JIF & $=1.500$ & SJIF (Morocco & $=5.667$ & OAJI (USA) & $=0.350$ \\
\hline
\end{tabular}

\begin{tabular}{|c|c|}
\hline \multicolumn{2}{|c|}{$\begin{array}{l}\text { SOI: } \frac{1.1 / \mathrm{TAS}}{\mathrm{DOI}} \underline{10.15863 / \mathrm{TAS}} \\
\text { International Scientific Journal } \\
\text { Theoretical \& Applied Science }\end{array}$} \\
\hline p-ISSN: 2308-4944 (print) & e-ISSN: 2409-0085 (online) \\
\hline Year: 2019 & Volume: 73 \\
\hline Published: 30.05 .2019 & http://T-Science.org \\
\hline
\end{tabular}

SECTION 9. Chemistry and chemical technology
QR - Issue

QR - Article

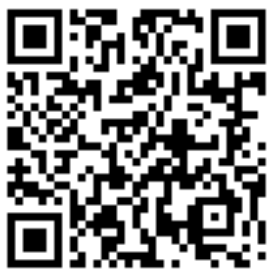

Malvina Tatvidze

Doctor of Chemical and Biological Engineering, Associated Professor, Faculty of Technological Engineering, Department of Chemical and Environmental Technologies, Akaki Tsereteli State University, Kutaisi, Georgia. (+995) 5995356 80; m.tatvidze@yahoo.com

Inga Bochoidze Doctor of Chemical Science, Professor, Head of Department, Faculty of Technological Engineering,

Department of Chemical and Environmental Technologies, Akaki Tsereteli State University, Kutaisi, Georgia. (+995) 5771318 28; bochoidze.inga@gmail.com

Elene Gamkrelidze Doctor of Chemical Science, Associated Professor, Faculty of Technological Engineering, Department of Chemical and Environmental Technologies, Akaki Tsereteli State University, Kutaisi, Georgia. (+995) 5776777 06;

Gamkrelidze.elen@gmail.com

\title{
DEVELOPMENT OF RECTAL SUPPOSITORIES BASED ON ALOE VERA FOR THE TREATMENT OF INFLAMMATORY DISEASES OF THE RECTUM
}

\footnotetext{
Abstract: The article describes the properties of the medicinal plant Aloe Vera. Aloe contains a huge amount of biologically active substances and used in the treatment of many diseases. The paper substantiates the possibility of developing therapeutic herbal suppositories containing aloe pulp. For the preparation of a suppository goat fat which has diphillic property is chosen as substances of the basis. Goat fat is a natural, less allergic product and easily melts at humans body temperature with the release of biologically active substances. With an appropriate technology is making suppository containing aloe pulp and goat fat on the basic. The mass of the suppository is $2 \mathrm{~g}$, it contains 1.2 $g$ of goat fat and $0.8 \mathrm{~g}$ of aloe pulp. Suppository can be used of the treatment proctitis, paraproctitis and other inflammatory diseases of the rectum. Aloe Vera has antioxidant, antiseptic, anti-inflammatory, hemostatic and healing properties, which is successfully combined with softening and regenerative properties of goat fat.

Key words: Aloe, goat fat, suppositories, inflammatory diseases of the rectum.

Language: Russian

Citation: Tatvidze, M. L., Bochoidze, I. G., \& Gamkrelidze, E. A. (2019). Development of rectal suppositories based on aloe vera for the treatment of inflammatory diseases of the rectum. ISJ Theoretical \& Applied Science, 05 (73), 371-374.

Soi: http://s-o-i.org/1.1/TAS-05-73-54 Doi: crossef https://dx.doi.org/10.15863/TAS.2019.05.73.54

РАЗРАБОТКА РЕКТАЛЬНЫХ СУППОЗИТОРИЕВ НА ОСНОВЕ АЛОЭ ДЛЯ ЛЕЧЕНИЯ ВОСПАЛИТЕЛЬНЫХ ЗАБОЛЕВАНИЙ ПРЯМОЙ КИШКИ
} 


\begin{tabular}{|c|c|c|c|c|c|c|}
\hline \multirow{4}{*}{ Impact Factor: } & ISRA (India) & $=3.117$ & SIS (USA) & $=0.912$ & ICV (Poland) & $=6.630$ \\
\hline & ISI (Dubai, UAE & $=0.829$ & РИНЦ (Russia & $=0.156$ & PIF (India) & $=1.940$ \\
\hline & GIF (Australia) & $=0.564$ & ESJI (KZ) & $=8.716$ & IBI (India) & $=4.260$ \\
\hline & JIF & $=1.500$ & SJIF (Morocco & $=5.667$ & OAJI (USA) & $=0.350$ \\
\hline
\end{tabular}

Аннотация: В статье рассмотрены лечебные свойства растения алоэ - Aloe vera. Приведены примеры применения алоэ для лечения разных заболеваний. Подтверждены возможности разработки лечебного растительного средства из мякоти алоэ. Для изготовления ректальных суппозиторий была выбрана дифильная основа - натуральный козый жир, который характеризуется менее аллергическими свойствами, легко плавится при температуре тела с высвобождением ряда лечебных веществ. С использованием соответствующей технологии были приготовлены супозиторы однородной зеленоватой окраски. Масса готовой формы суппозитория - 2 г, содержит 1,2 г козьего жира и 0,8 г мякоти алоэ. В лечебных суппозиториях антисептические, противовоспалительные, заживающие свойства мякоти алоэ находятся в уникальной композищии со смягчающими и регенерирующими свойствами козьего жира. Супозитории можно применять для лечения проктитов, парапроктитов и других воспалительных заболеваний прямой кишки.

Ключевые слова: Алое, козий жир, суппозитории, воспалительные заболевания прямой кишки.

\section{Introduction}

Цель исследований - разработка лечебного средства в форме суппозитории, где активным ингредиентом является мякоть лечебного растения алоэ, а в качестве основы представлен козий жир.

Алоэ - Aloe vera многолетнее растение. В Фармакопее Грузии занесено как лечебное растение. Его листья содержат большой перечень гликозидов: алоизин, алоин, емодин, хризофанол и др.

\section{Materials and Methods}

Учеными разных стран были исследованы и изучены более 20 важнейших компонентов, входящих в состав алоэ, которые имеют высокую биологическую активность. Листья алое содержат витамины А, E, С и широкий спектр витаминов группы В. Алоэ содержит до 16 наименований жирных насыщенных и ненасыщенных кислот [1, c. $35-38 ; 2 ; 3$, c. $259-272 ; 4$, с. 141-148].

Из фенольных соединений особый интерес заслуживают эмодин и хризофанол, которые относятся к группе антрахинонов. Эмодин имеет выраженное антибактериальное и болеутоляющее свойства, а хризофанол обладает гемостатической активностью. Из-за наличия этих биологически активных веществ свежевыжатый сок алое издавна применяли в народной медицине для лечения воспалительных заболеваний прямой кишки. Традиционно народные лекари лечили соком алое в виде примочек и тампонов, что достаточно сложная манипуляция и связана с определенными неудобствами.

Для изготовления ректальных суппозиторий на базе мякоти алое нами выбрана дифильная основа - натуральный козьи жир.

К основам суппозитории предъявляются следующие требования: хорошая совместимость с ингредиентами в лечебном средстве, отсутствие раздражающего действия на слизистые оболочки, стабильность при хранении и др. А также, основа при комнатной температуре должна сохранять нужную консистенцию, чтобы не произошла деформация суппозитория, а при температуре тела должна плавится и высвобождать лекарственные субстанции.

Различают несколько типов основ лекарственных суппозиторий. К липофильным основам относятся масло какао, парафин, ланолин, спермацет; гидрофильные основы полиэтиленоксиды, желатино-глицериновая смесь и др. Существуют также дифильные основы, которые равномерно хорошо присоединяют как жидкие, так и жировые компоненты.

К дифильным основам относят в основном животные жиры: козий, медвежий, заячий и др. Козий жир содержит кальций, фосфор, магний, аскорбиновую кислоту, балансированное количество насыщенных и ненасыщенных жирных кислот и много других полезных веществ [5, с. 255-268; 6, с.1191-1193]. Козий жир считается менее аллергическим натуральным жиром и характеризуется высокой биодоступностью. Козий жир восстанавливает поврежденные клетки тканей и обладает выраженным смягчающим действием. Оптимальная температура плавления козьего жира $37^{0} \mathrm{C}$, что особенно важно, так как он легко и быстро плавится при температуре тела, с высвобождением и последующим равномерным распределением лечебных субстанций.

Наша цель - разработка ректального суппозитория из мякоти алоэ. Технологическая схема приготовления суппозитория представлена в следующем виде [7, с. 418-424]:

Изначально провели ферментацию мякоти алоэ. Срезали листья алоэ и поместили в темное и прохладное помещение, в течение 2-х недель. За это время под воздействием кислорода происходят сложные химические превращения. Начинается начальный процесс брожения, листья растения меняют цвет и запах, происходит высвобождение биологически активных веществ из внутриклеточного пространства, что способствует увеличению его биодоступности в организм человека.

Ферментированные листья алоэ максимально диспергировали в дробильно-смешивающем приборе. Была получена кашеобразная масса темно-зеленного цвета, которая после 12-15 


\begin{tabular}{llllll} 
& ISRA (India) $=\mathbf{3 . 1 1 7}$ & SIS (USA) & $=\mathbf{0 . 9 1 2}$ & ICV (Poland) & $=\mathbf{6 . 6 3 0}$ \\
Impact Factor: & ISI (Dubai, UAE) $=\mathbf{0 . 8 2 9}$ & PUHЦ (Russia) $=\mathbf{0 . 1 5 6}$ & PIF (India) & $=\mathbf{1 . 9 4 0}$ \\
& GIF (Australia) $=\mathbf{0 . 5 6 4}$ & ESJI (KZ) & $=\mathbf{8 . 7 1 6}$ & IBI (India) & $=\mathbf{4 . 2 6 0}$ \\
JIF & $=\mathbf{1 . 5 0 0}$ & SJIF (Morocco) $=\mathbf{5 . 6 6 7}$ & OAJI (USA) & $\mathbf{0 . 3 5 0}$ \\
\hline
\end{tabular}

минутного отстаивания выделяла водную фракцию.

В нагревательном приборе растопили 48 г козьего жира (рис. 1).

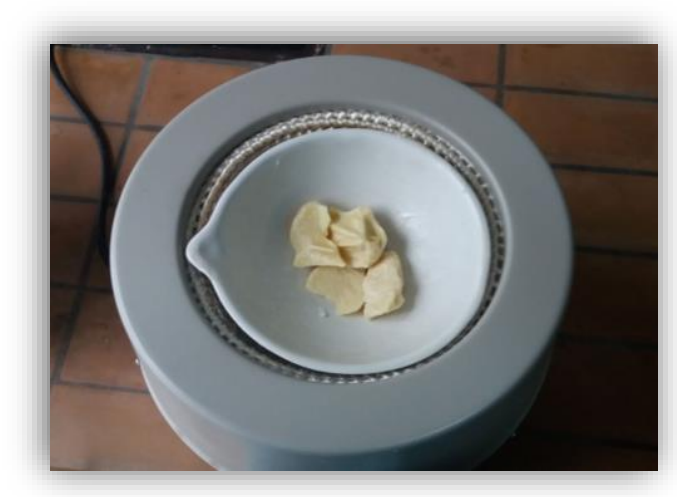

Рис. 1. Нагрев козьего жира

Контролировали температуру (макс. $45^{\circ} \mathrm{C}$ ). В полученную массу добавили 32 г предварительно диспергированную мякоть алоэ и провели гомогенизацию в течение 8-10 минут (рис. 2).
Следует отметить, что указанные количества композитов были установлены на основе предварительных исследований.

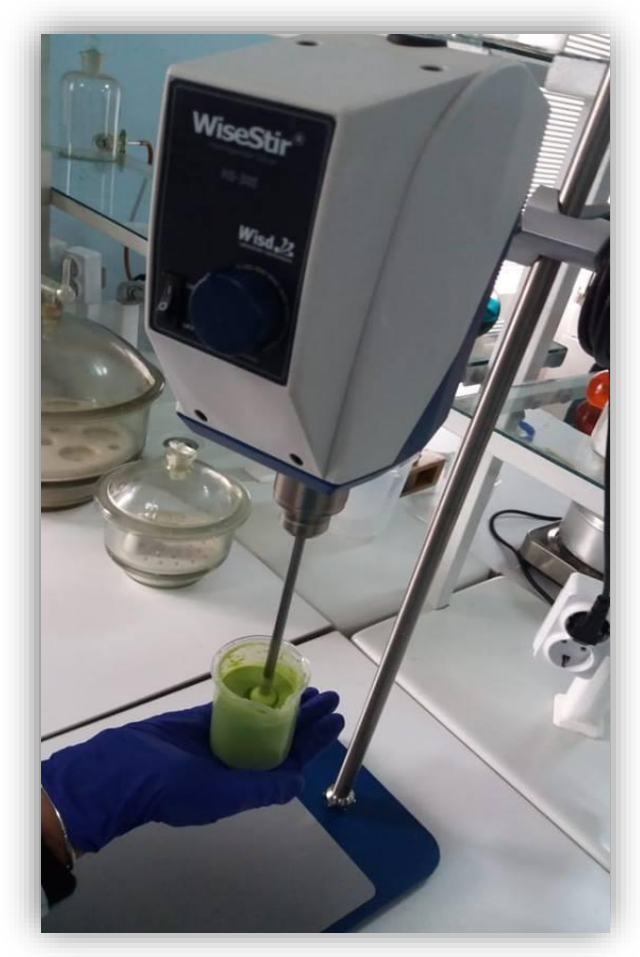

Рис. 2. Гомогенизация смеси на гомогенизаторе WiseStir Homogenizer Stirrer HS-30E

Перед отливкой полученную массу быстро растопили до текучего состояния и залили в специальную форму для приготовления суппозиториев. Отливка проходила максимально быстро для предотвращения расслаивания. Форму поместили в холодильник в течение 60 минут. Готовые суппозитории зеленного цвета, с характерным запахом, имеют однородную плотную консистенцию и одинаковую торпедообразную (ректальную) форму, температура плавления $37^{0} \mathrm{C}$, длина 2,5 см, диаметр основы - 1 см. При комнатной температуре сохраняет форму и стабильность в течение 15 минут. На рис. 3 представлены ректальные суппозиторий из мякоти алое после 


\begin{tabular}{|c|c|c|c|c|c|c|}
\hline \multirow{4}{*}{ Impact Factor: } & ISRA (India) & $=3.117$ & SIS (USA) & $=0.912$ & ICV (Poland) & $=6.630$ \\
\hline & ISI (Dubai, UAE & $=0.829$ & РИНЦ (Russia & $=0.156$ & PIF (India) & $=1.940$ \\
\hline & GIF (Australia) & $=0.564$ & ESJI (KZ) & $=8.716$ & IBI (India) & $=4.260$ \\
\hline & JIF & $=1.500$ & SJIF (Morocco & $=5.667$ & OAJI (USA) & $=0.350$ \\
\hline
\end{tabular}

доставки из формы для приготовления суппозиториев.

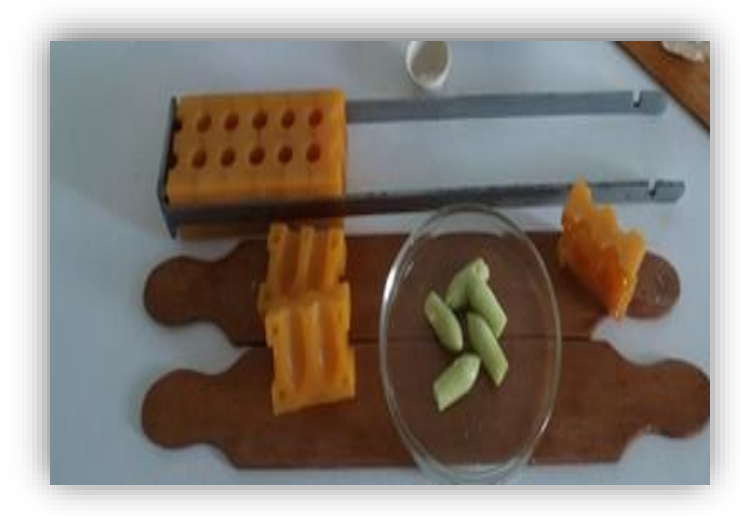

Рис. 3. Готовые ректальные суппозитории

\section{Conclusion}

В результате проведенных исследований нами был предложен лечебный суппозиторий из мякоти листьев алое на основе козьего жира, в соотношении 6:9.

- Масса лечебного ректального суппозитория -2 г

- Активный ингредиент - мякоть алоэ - 0,8

$\Gamma$

- Основа - козий жир - 1,2 г.
Вывод: разработано новое лечебное средство в виде ректальных суппозиториев, обладающее антисептическим, противовоспалительным, заживающим и гемостатическим свойствами. Суппозитории можно применять для лечения проктитов, парапроктитов и ряда воспалительных заболеваний прямой кишки [8, с. $129 ; 9$, с. 165; 10, c. 13-16]. В новом средстве лечебные свойства мякоти листьев алоэ находятся в уникальной комбинации со смягчающими и регенерирующими свойствами козьего жира.

\section{References:}

1. Moiseev, D. V., Buzuk, G. N., \& Shelyuto, V. L. (2011). Identifikatsiya flavonoidov v rasteniyah metodom VEZhH. Himiko-farmatsevticheskiy zhurnal, 45(1), pp.35-38.

2. Hashemi, S. A., Madani, S. A., \& Abediankenari, S. (2015). The review on properties of Aloe vera in healing of cutaneous wounds. BioMed research international.

3. Dalton, T., \& Cupp, M. J. (2000). Aloe. In Toxicology and Clinical Pharmacology of Herbal Products (pp. 259-272). NJ: Humana Press, Totowa.

4. Trineeva, O. V., Sinkevich, A. V., \& Slivkin, A. I. (2015). Issledovanie aminokislotnogo sostava izvlecheniy iz rastitelınyih obъektov. Himiya rastitelnogo syirya. 2 (apr. 2015), 141-148. DOI: https://doi.org/10.14258/jcprm.201502292

5. Banskalieva, V., Sahlu, T. A., \& Goetsch, A. L. (2000). Fatty acid composition of goat muscles and fat depots: a review. Small Ruminant Research, 37(3), pp.255-268.
6. Park, Y. W., Kouassi, M. A., \& Chin, K. B. (1991). Moisture, total fat and cholesterol in goat organ and muscle meat. Journal of Food Science, 56(5), pp.1191-1193.

7. Grigorevskiy, V. P., \& Konev, F. A. (2000). Tehnologiya i standartizatsiya lekarstvennyih sredstv. Sbornik nauchnyih trudov, «Rager», Harkov. T. 2, pp.418-424.

8. Kuhtenko, A. S., \& Ruban, O. A. (2004). Aktualnyie problemyi sozdaniya novyih lekarstvennyih preparatov dlya lecheniya proktologicheskih zabolevaniy. Naukove vidannya, p.129.

9. Gupta, P. J. (2007). Suppositories in anal disorders: a review. European review for medical and pharmacological sciences, 11(3), p. 165 .

10. Bolkvadze, E. E., \& Egorkin, M. A. (2012). Classification and treatment of complex forms of acute paraproctitis. Fifteen years of experience. Koloproktologiia, 2: pp.13-16. 